\title{
Article \\ Genetic Alterations and Resectability Predict Outcome in Patients with Neuroblastoma Assigned to High-Risk Solely by MYCN Amplification
}

\author{
Frank Berthold $1, *,+\oplus$, Angela Ernst ${ }^{2, \dagger}$, Sandra Ackermann ${ }^{3}$, Christoph Bartenhagen ${ }^{3}$, Holger Christiansen ${ }^{4}$, \\ Barbara Hero ${ }^{1} \oplus$, Carolina Rosswog ${ }^{3,5}$, Dietrich von Schweinitz ${ }^{6}$, Thomas Klingebiel ${ }^{7}$, Irene Schmid ${ }^{6}$, \\ Thorsten Simon ${ }^{1}\left(\mathbb{D}\right.$ and Matthias Fischer ${ }^{3}$
}

Citation: Berthold, F.; Ernst, A.; Ackermann, S.; Bartenhagen, C.; Christiansen, H.; Hero, B.; Rosswog, C.; von Schweinitz, D.; Klingebiel, T.; Schmid, I.; et al. Genetic Alterations and Resectability Predict Outcome in Patients with Neuroblastoma Assigned to High-Risk Solely by MYCN Amplification. Cancers 2021, 13, 4360. https://doi.org/10.3390/ cancers 13174360

Academic Editor: Mojgan Rastegar

Received: 24 July 2021

Accepted: 24 August 2021

Published: 28 August 2021

Publisher's Note: MDPI stays neutral with regard to jurisdictional claims in published maps and institutional affiliations.

Copyright: (c) 2021 by the authors. Licensee MDPI, Basel, Switzerland. This article is an open access article distributed under the terms and conditions of the Creative Commons Attribution (CC BY) license (https:// creativecommons.org/licenses/by/ $4.0 /)$.
1 Department of Pediatric Oncology and Hematology, University of Cologne, Kerpener Str. 62, 50924 Cologne, Germany; barbara.hero@uk-koeln.de (B.H.); thorsten.simon@uk-koeln.de (T.S.)

2 Institute of Medical Statistics and Computational Biology, Medical Faculty, University of Cologne, 50924 Cologne, Germany; angela.ernst@uk-koeln.de

3 Center for Molecular Medicine Cologne (CMMC) and Department of Experimental Pediatric Oncology, Medical Faculty, University of Cologne, Kerpener Str. 62, 50924 Cologne, Germany; sandra.ackermann@uk-koeln.de (S.A.); c.bartenhagen@uni-koeln.de (C.B.); carolina.rosswog@uk-koeln.de (C.R.); matthias.fischer@uk-koeln.de (M.F.)

4 Department of Pediatric Oncology, Hematology and Hemostasiology, University of Leipzig, Liebigstr. 20a, 04103 Leipzig, Germany; holger.christiansen@medizin.uni-leipzig.de

5 Else Kröner Forschungskolleg Clonal Evolution in Cancer, University Hospital Cologne, Kerpener Str. 62, 50924 Cologne, Germany

6 Department of Pediatric Surgery, von Hauner Children's Hospital, Ludwig-Maximilians-University Munich, Lindwurmstr. 4, 80337 München, Germany; dietrich.schweinitz@med.uni-muenchen.de (D.v.S.); irene.schmid@med.uni-muenchen.de (I.S.)

7 Department of Children and Adolescents, University Hospital, Goethe University Frankfurt, Theodor-Stern-Kai 7, 60596 Frankfurt, Germany; thomas.klingebiel@kgu.de

* Correspondence: frank.berthold1@uk-koeln.de

+ These two authors are contributed equally to this manuscript.

Simple Summary: Currently, patients with high-risk neuroblastoma are uniformly treated with maximum therapy. This study investigated a high-risk subgroup characterized by the presence of the amplified MYCN oncogene in the tumor regardless of the stage. In contrast to the corresponding high-risk subgroup consisting of patients with metastases and age at diagnosis over 18 months, the investigated subgroup had generally a superior survival chance. However, the detection of mutations of specific genes in the tumor tissue (RAS and p53 pathway including ALK) had a strong, negative impact. These genes should be therefore also investigated in the future. Complete surgical removal of the primary tumor proved to be beneficial for high-risk neuroblastoma patients assigned to the high-risk category solely by MYCN amplification.

Abstract: Background: To identify variables predicting outcome in neuroblastoma patients assigned to the high-risk group solely by the presence of $M Y C N$ oncogene amplification (MNA). Methods: Clinical characteristics, genomic information, and outcome of 190 patients solely assigned to high-risk neuroblastoma by MNA were analyzed and compared to 205 patients with stage 4 neuroblastoma aged $\geq 18$ months with MNA (control group). Results: Event-free survival (EFS) and overall survival (OS) at 10 years were 47\% (95\%-CI 39-54\%) and 56\% (95\%-CI 49-63\%), respectively, which was significantly better than EFS and OS of the control group (EFS 25\%, 95\%-CI 18-31\%, $p<0.001$; OS $32 \% 95 \%$-CI 25-39\%, $p<0.001$ ). The presence of RAS-/p53-pathway gene alterations was associated with impaired 10 -year EFS and OS (19\% vs. 55\%, and 19\% vs. $67 \%$, respectively; both $p<0.001)$. In time-dependent multivariable analyses, alterations of RAS-/p53-pathway genes and the extent of the best primary tumor resection were the only independent prognostic variables for OS $(p<0.001$ and $p=0.011$, respectively). Conclusions: Neuroblastoma patients attributed to high risk solely by MYCN amplification have generally a more favorable outcome. Mutations of genes of the RAS and/or p53 pathways and incomplete resection are the main risk factors predicting poor outcome. 


\section{Introduction}

Neuroblastoma is considered as high-risk if the calculated 5-year event-free survival is below $50 \%$ for de novo patients. To this category belong patients with distant metastases aged $\geq 18$ months at diagnosis (stage $4 / \mathrm{M}$ ) and those with $M Y C N$ amplification (MNA) regardless of their stage (1-3, 4S/MS, 4/M) and age [1-3]. The significance of MNA for unfavorable outcomes has been demonstrated in patients with localized neuroblastoma (stages 1, 2,3/L1-2) [4-8], stage 4S/MS patients [9,10], and also stage 4/M patients aged less than 18 months at diagnosis [2,11,12]. Thus, there is strong evidence that patients with $M Y C N$-amplified neuroblastoma who are otherwise at low or intermediate risk have an inferior prognosis compared to those without MNA.

In the literature, the mentioned criteria are not strictly observed. Studies on outcome of high-risk neuroblastoma patients commonly report two categories, i.e., those diagnosed as stage 4 over the age of 18 months (major group) and those assigned to high risk due to other criteria (minor group). Various definitions of the minor group using distinct criteria, e.g., MNA, stage 3 without MNA, unfavorable histology, and unfavorable ploidy, have resulted in variable sizes and limited comparability of minor groups in different studies. Nonetheless, the outcome of these patients was generally more favorable compared to the major group, although outcomes were rarely reported separately [4-6,8,11-13], impeding comparisons of results from different trials for high-risk neuroblastoma.

The impact of the varying definitions and conditions is highlighted by the role of surgery in high-risk neuroblastoma. The SIOPEN group reported an improved survival for stage 4 patients who responded to induction chemotherapy and had complete macroscopical excision of the primary tumor (plus high-dose chemotherapy, local radiotherapy and immunotherapy) [14]. In another smaller study, stage 4 patients with poor response to induction chemotherapy had no outcome benefit from a higher extent of primary tumor resection [15]. The German group found no impact of the extent of surgical resection on outcome in high-risk stage 4 patients aged over 18 months [16]. A systematic review and meta-analysis demonstrated some advantage for gross total resection regarding diseasefree survival; however, OS was not improved in stage 4 disease [17]. The time point of the surgical intervention (at diagnosis vs. delayed after induction chemotherapy) may also play a role (reflecting the grade of initial resectability?) [18]. These partially conflicting results from different studies and different cohorts suggest that subgroup investigations on the role of surgery may be meaningful.

It has recently been demonstrated that the presence of telomere maintenance mechanisms and mutations of genes of the RAS- and p53-pathway are major determinants of clinical courses in neuroblastoma $[19,20]$. Telomere maintenance may result from various genomic alterations, including MNA [21]. It has remained unclear, however, whether mutations in the pre-defined set of genes related to the RAS-/p53-pathway [19] impact clinical outcomes of the subgroup of children with MNA but otherwise low- or intermediate-risk characteristics.

Thus, we here aimed to examine the clinical and genetic characteristics together with the effect of time-dependent and -independent therapeutic interventions on the outcome of neuroblastoma patients considered high risk solely due to MNA.

\section{Patients and Methods}

Inclusion criteria for the study group were (i) neuroblastoma with INSS stages 1 , 2, or 3 [22] of all ages, or stage 4S, or stage 4 aged $<18$ months at diagnosis; (ii) MYCN amplification (>4-fold MYCN copy number in relation to the copy number of chromosome 2 [23]); (iii) registration in the trial NB97 (high-dose arm, as treated) or the NB2004-HR trial (experimental and standard arm [24]); and (iv) diagnosis between 5 March 1997 and 31 December 2016. Exclusion criteria were (i) second malignancy after neuroblastoma 
diagnosis, (ii) withdrawal of consent for data use, and (iii) loss to follow-up before first chemotherapeutic course.

High-risk patients with stage 4 aged $\geq 18$ months at diagnosis with MNA served as the control group. All other inclusion and exclusion criteria were identical to the study group.

Patients were treated according to the high-risk strata of trials NB97 and NB-2004HR [13]. The high-dose arm of trial NB97 was adopted as the standard in the NB2004-HR protocol [25], and outcome results of the two NB2004-HR arms were identical. Therefore, treatment efficacy was considered to be identical between the high-dose arm of NB97 and the two arms of NB2004-HR. Anti-GD2 antibody therapy was included during the period 1997-2002 of the NB97 trial. Afterwards, antibody therapy was not protocol treatment until 2016 [24].

The primary endpoint was event-free survival (EFS). The analyses are regarded as exploratory, and $p$-values are given as descriptive measures to detect meaningful effects. EFS was defined as the time from the date of diagnosis until recurrence or progress or until death of any cause or until the last examination. Overall survival (OS) was calculated from the date of diagnosis until death of any cause or until the last examination. Kaplan-Meier estimates for EFS and OS were compared by log-rank tests or the Fleming-Harrington $p$-value if the proportional hazards assumption did not hold.

Univariable analysis was used to investigate the individual prognostic impact of risk factors, which are indicated in Table 1. For multivariable survival analyses the Cox regression model was used. After testing for multicollinearity, included variables were chromosome $1 \mathrm{p}$ aberrations, primary tumor site (cervical, thoracic, adrenal, abdominal non-adrenal, unknown, $>1$ site, combined regions, $>1$ site multilocular), initial number of metastatic organs), sex, age, stage, best result of surgical resection regardless of the time point and the number of operations (at diagnosis or after preceding chemotherapy, first or second look surgery), lactic dehydrogenase (LDH), ferritin, homovanillic acid (HVA) and/or vanillylmandelic acid (VMA), neuron-specific enolase (NSE), percutaneous radiotherapy, antibody therapy, metaiodinebenzylguanidine (mIBG) therapy, high-dose chemotherapy with autologous stem cell support (ASCT), and RAS and/or p53 pathway alterations. The covariates were fitted into a stepwise model selection process (forward and backward with Akaike Information Criterion (AIC) to select the better fitting model) and the proportional hazards assumption tested in the final models. The likelihood ratio test $p$-value for inclusion was $\leq 0.05$ and for exclusion $>0.10$. Estimated hazard ratios (HR) with $95 \%$ confidence intervals $(95 \% \mathrm{CI})$ and Wald $p$-values were calculated. For all analyses, IBM SPSS statistical package version 26 and $\mathrm{R}$ version 4.0.3 were used. The data lock for this analysis was 24 March 2020.

Table 1. Patient characteristics.

\begin{tabular}{|c|c|c|c|}
\hline Characteristic & $\begin{array}{c}\text { Study Group } \\
\text { Stages } 1,2,3,4 \mathrm{~S}, 4<18 \mathrm{~m} \\
N(\%)\end{array}$ & $\begin{array}{c}\text { Control Group } \\
\text { Stage } 4 \geq 18 \mathrm{~m} \text { and MNA } \\
N(\%)\end{array}$ & $p$ \\
\hline All & $190(100)$ & $205(100)$ & \\
\hline Sex & $190(100)$ & $205(100)$ & \\
\hline Male & $111(58)$ & $124(60.5)$ & 0.683 \\
\hline Female & $79(42)$ & $81(39.5)$ & \\
\hline Age at diagnosis (m) & $190(100)$ & $205(100)$ & \\
\hline Median (inter-quartile range) & $14.3(9.0-26.0)$ & $30.5(24.1-43.9)$ & $<0.001 * *$ \\
\hline
\end{tabular}


Table 1. Cont.

\begin{tabular}{|c|c|c|c|}
\hline Characteristic & $\begin{array}{c}\text { Study Group } \\
\text { Stages } 1,2,3,4 \mathrm{~S}, 4<18 \mathrm{~m} \\
N(\%)\end{array}$ & $\begin{array}{c}\text { Control Group } \\
\text { Stage } 4 \geq 18 \mathrm{~m} \text { and MNA } \\
N(\%)\end{array}$ & $p$ \\
\hline Primary tumor site & $190(100)$ & $205(100)$ & \\
\hline Abdominal adrenal & $132(70)$ & $143(70)$ & $>0.999$ \\
\hline Abdominal non-adrenal & $53(28)$ & $59(29)$ & 0.911 \\
\hline Thoracic & $12(6)$ & $18(9)$ & 0.448 \\
\hline Cervical & $1(1)$ & $2(1)$ & N.A. \\
\hline Unknown & $0(0)$ & $0(0)$ & N.A. \\
\hline$>1$ site (combined regions) & $8(4)$ & $14(7)$ & 0.280 \\
\hline$>1$ site (multilocular) & $8(4)$ & $3(2)$ & 0.128 \\
\hline Stage (INSS) & $190(100)$ & $205(100)$ & \\
\hline $1,2,3$ or $4 S$ & $119(63)$ & $0(0)$ & N.A. \\
\hline 1 & $5(3)$ & $0(0)$ & N.A. \\
\hline 2 & $20(10)$ & $0(0)$ & N.A. \\
\hline 3 & $68(36)$ & $0(0)$ & N.A. \\
\hline $4 S$ & $26(14)$ & $0(0)$ & N.A. \\
\hline $4<18 \mathrm{~m}$ & $71(37)$ & $0(0)$ & N.A. \\
\hline $4 \geq 18 \mathrm{~m}$ & $0(0)$ & $205(100)$ & N.A. \\
\hline Sites of initial metastasis stage 4 & $\begin{array}{l}\text { Stage } 4<18 \mathrm{~m} \\
71(100)\end{array}$ & $\begin{array}{c}\text { Stage } 4 \geq 18 \mathrm{~m} \text { and MNA } \\
205(100)\end{array}$ & \\
\hline Bone marrow (cytology) & $65(92)$ & $189(92)$ & 0.804 \\
\hline $\begin{array}{c}\text { Osteomedullary (mIBG } \\
\text { scintigraphy) }\end{array}$ & $67(94)$ & $196(96)$ & 0.746 \\
\hline Lymph nodes & $20(28)$ & 55 (27) & 0.877 \\
\hline Liver & $20(28)$ & $24(12)$ & 0.002 \\
\hline Brain/spinal cord & $2(3)$ & $9(4)$ & 0.734 \\
\hline Lung/pleura & $8(11)$ & $16(8)$ & 0.463 \\
\hline Skin & $2(3)$ & $0(0)$ & N.A. \\
\hline Soft tissue & $5(7)$ & $3(2)$ & 0.029 \\
\hline Other & $2(3)$ & $2(1)$ & 0.273 \\
\hline Osteomedullary only & $30(42)$ & $117(57)$ & 0.038 \\
\hline Sites of initial metastasis stage $4 \mathrm{~S}$ & $\begin{array}{l}\text { Stage } 4 S \\
26(100)\end{array}$ & $\begin{array}{c}\text { Stage } 4 \geq 18 \mathrm{~m} \text { and MNA } \\
205(100)\end{array}$ & \\
\hline Bone marrow (cytology) & $17(14)$ & $189(92)$ & $<0.001$ \\
\hline $\begin{array}{c}\text { Osteomedullary (mIBG } \\
\text { scintigraphy) }\end{array}$ & $17(62)$ & $196(96)$ & $<0.001$ \\
\hline Lymph nodes & $0(0)$ & $55(27)$ & $<0.001$ \\
\hline Liver & $22(19)$ & $24(12)$ & 0.101 \\
\hline Brain/spinal cord & $0(0)$ & $9(4)$ & N.A. \\
\hline Lung/pleura & $1(1)$ & $16(8)$ & 0.008 \\
\hline Skin & $2(3)$ & $0(0)$ & N.A. \\
\hline Soft tissue & $0(0)$ & $3(2)$ & N.A. \\
\hline Other & $0(0)$ & $2(1)$ & N.A. \\
\hline Osteomedullary only & $3(10)$ & $117(57)$ & $<0.001$ \\
\hline Tumor marker (NSE) & $167(100)$ & $188(100)$ & \multirow{3}{*}{0.192} \\
\hline Normal & $4(2)$ & $1(1)$ & \\
\hline abnormal & $163(98)$ & $187(99)$ & \\
\hline Tumor marker (VMA/HVA) & $190(100)$ & $205(100)$ & \multirow[b]{3}{*}{0.007} \\
\hline normal & $59(31)$ & $39(19)$ & \\
\hline Abnormal & $131(69)$ & $166(81)$ & \\
\hline Tumor marker LDH & $185(100)$ & $202(100)$ & \multirow[b]{3}{*}{0.016} \\
\hline Normal & $8(4)$ & $1(0)$ & \\
\hline abnormal & $177(96)$ & $201(100)$ & \\
\hline Tumor marker ferritin & $142(100)$ & 166 & \multirow[b]{3}{*}{0.002} \\
\hline Normal & $76(53)$ & $59(35)$ & \\
\hline Abnormal & $66(47)$ & $107(65)$ & \\
\hline
\end{tabular}


Table 1. Cont.

\begin{tabular}{|c|c|c|c|}
\hline Characteristic & $\begin{array}{c}\text { Study Group } \\
\text { Stages } 1,2,3,4 S, 4<18 \mathrm{~m} \\
N(\%)\end{array}$ & $\begin{array}{c}\text { Control Group } \\
\text { Stage } 4 \geq 18 \mathrm{~m} \text { and MNA } \\
N(\%)\end{array}$ & $p$ \\
\hline Histology (Shimada) & $163(100)$ & $164(100)$ & \multirow[b]{3}{*}{$<0.001$} \\
\hline Favorable & $42(26)$ & $7(4)$ & \\
\hline Unfavorable & $121(74)$ & $157(96)$ & \\
\hline Chromosome 1p aberration & $175(100)$ & $188(100)$ & \multirow{4}{*}{0.155} \\
\hline Heterozygosity & $25(14)$ & $32(17)$ & \\
\hline Imbalance & $25(14)$ & $39(21)$ & \\
\hline Deletion & $125(71)$ & $117(62)$ & \\
\hline Mutation RAS/p53 & $87(100)$ & $49(100)$ & \multirow{2}{*}{0.081} \\
\hline yes & $21(24)$ & $19(39)$ & \\
\hline Treatment protocol & $190(100)$ & $205(100)$ & \multirow{3}{*}{0.137} \\
\hline NB 97 & $57(30)$ & $47(23)$ & \\
\hline NB 2004 & $133(70)$ & $158(77)$ & \\
\hline Surgery * & $190(100)$ & $205(100)$ & \multirow{5}{*}{0.960} \\
\hline Complete resection & $90(47)$ & $95(46)$ & \\
\hline Incomplete resection & $66(35)$ & $71(35)$ & \\
\hline Biopsy only & $19(10)$ & $21(10)$ & \\
\hline No surgery & $15(8)$ & $18(9)$ & \\
\hline Radiotherapy & $190(100)$ & $205(100)$ & \multirow{3}{*}{0.282} \\
\hline Not given & $177(93)$ & $184(90)$ & \\
\hline Given & $13(7)$ & $21(10)$ & \\
\hline mIBG therapy & $190(100)$ & $205(100)$ & \multirow[b]{3}{*}{0.003} \\
\hline Not given & $171(90)$ & $43(21)$ & \\
\hline Given & $19(10)$ & $162(79)$ & \\
\hline ASCT & $190(100)$ & $205(100)$ & \multirow{3}{*}{0.243} \\
\hline Given & $151(79.5)$ & $172(84)$ & \\
\hline Not given & $39(20.5)$ & $33(16)$ & \\
\hline Antibody therapy & $190(100)$ & $205(100)$ & \multirow{3}{*}{0.245} \\
\hline Given & $30(16)$ & $24(12)$ & \\
\hline Not given & $160(84)$ & $181(88)$ & \\
\hline Treatment modalities & $190(100)$ & $205(100)$ & \multirow{5}{*}{0.294} \\
\hline Neither surgery nor CT & $1(1)$ & $0(0)$ & \\
\hline Surgery only & $1(1)$ & $0(0)$ & \\
\hline CT only & $14(7)$ & $18(9)$ & \\
\hline Surgery and CT & $174(92)$ & $187(91)$ & \\
\hline \multicolumn{4}{|l|}{ Follow-up (years) } \\
\hline $\begin{array}{l}\text { Median } \\
\text { [inter-quartile range; } \\
\text { min-max] }\end{array}$ & $\begin{array}{c}4.1 \\
{[1.2-11.4 ; 0.0-22.5]}\end{array}$ & $\begin{array}{c}2.7 \\
{[1.2-6.3 ; 0.0-22.2]}\end{array}$ & 0.018 \\
\hline Cause of death & $83(100)$ & $133(100)$ & \multirow{4}{*}{0.333} \\
\hline Tumor & $72(87)$ & $116(87)$ & \\
\hline Toxicity & $11(13)$ & $14(11)$ & \\
\hline Tumor or toxicity & $0(0)$ & $3(2)$ & \\
\hline
\end{tabular}

ASCT: high-dose chemotherapy with autologous blood stem cell transplantation. LDH: lactate dehydrogenase. m: months. mIBG: metaiodinebenzylguanidine (scintigraphy, therapy). $N$ : number of patients per group. N.A.: not applicable. NSE: neuron-specific enolase. VMA/HVA: vanillylmandelic acid and/or homovanillic acid in urine. \% percent of patients per group. * Surgery performed before first recurrence; best result if $>1$ operation. ${ }^{* *}$ Mann Whitney test.

Chromosome 1p aberrations and copy numbers of the oncogene $M Y C N$ were investigated twice per tissue sample by two independent laboratories and analyzed according to the international consensus [23,26]. All tumors of the study cohort were considered to be telomerase-positive because telomerase-reverse-transcriptase (TERT) is transcriptionally 
activated by $M Y C N$, as demonstrated previously [21,27]. Genes related to the RAS and p53 pathways were defined according to Ackermann et al. [19] and included ALK as an upstream activator of the RAS-MAPK pathway. Genomic alterations affecting these genes were determined by massively parallel sequencing, as described previously [19]. Of the 87 study patients, 56 were already reported (with less corresponding clinical details) [19].

\section{Results}

Within the investigation period, 823 patients with high-risk neuroblastoma were enrolled in the trials NB97 (high-dose chemotherapy arm) and NB2004 (both high-risk arms). Of these, 193 (23.5\%) were considered as high risk solely by MNA. Three patients were excluded (Figure 1), resulting in 190 patients for analysis, referred to as the study group. The control group consisted of 205 high-risk patients aged $\geq 18$ months with stage 4 disease and MNA.

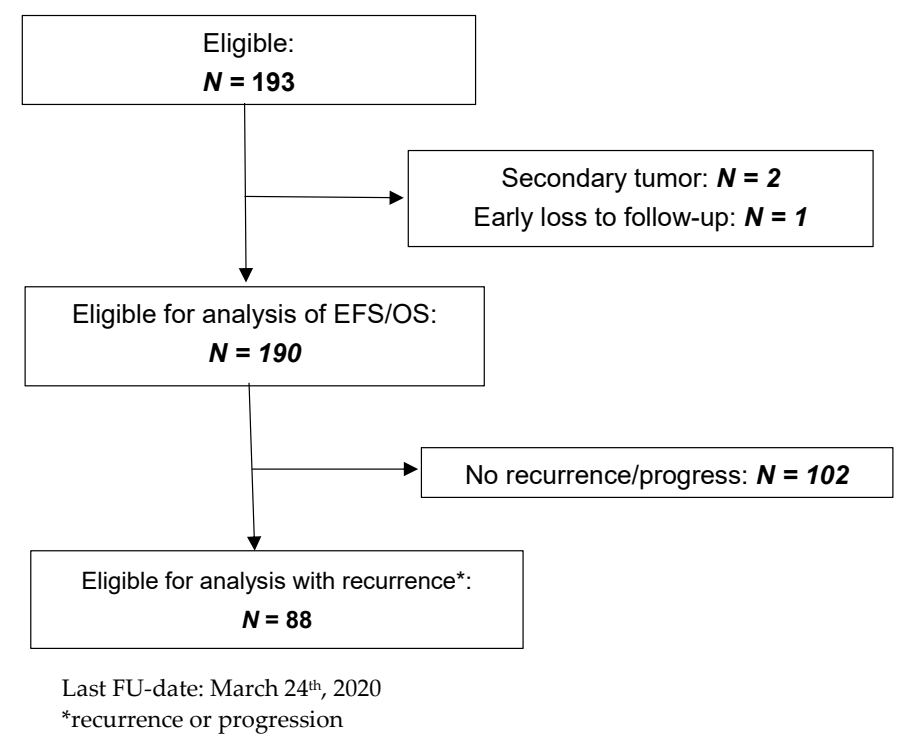

Figure 1. CONSORT diagram.

\subsection{Characteristics of the Patients and Tumors}

Of the 190 study patients, 93 had localized disease (49\%), 26 had stage $4 \mathrm{~S}(14 \%)$, and $71(37 \%)$ had stage 4 and were $<18$ months at diagnosis (Table 1$)$. Study patients had less frequently elevated tumor markers and unfavorable histology [28] compared to the control group (Table 1). Patients with stage 4 aged $<18$ months had more frequent liver metastasis compared to those aged $\geq 18$ months at diagnosis ( $28 \%$ vs. $12 \%$ ).

The frequency of losses at the short arm of chromosome 1 did not differ between tumors of the study and control group. Information on genomic alterations of genes of the RAS and p53 pathway [19] was available from 87 patients of the study group and from 49 patients of control group. In the study group, the outcome of patients with and without such information did not differ ( $p=0.612$ for EFS and $p=0.633$ for OS), indicating that there was no systematic selection bias between these cohorts. The same was true for the control group ( $p=0.590$ for EFS and $p=0.083$ for OS). Mutations in RAS/p53 pathway-related genes tended to occur less frequently in the study than in control group (24\% $(21 / 87$ cases) vs. $39 \%$ (19/49 cases)), with the majority of alterations affecting ALK both in the study and control group (Table 2). 
Table 2. Type of mutations in the study group $(N=22$ in 21 patients $)$ and the control group $(N=22$ in 19 patients).

\begin{tabular}{ccc}
\hline Gene & Study Group & Control Group \\
\hline ALK mutations & $8^{*}$ & $7 \#$ \\
ALK amplifications & 4 & 3 \\
HRAS & 1 & $1 \#$ \\
NRAS & 1 & 0 \\
KRAS & 0 & 1 \\
NF1 & 1 & $1 \#$ \\
LIN28B & 1 & 0 \\
CCND1 & 1 & 0 \\
FGFR1 & 0 & 1 \\
PTPN11 & 0 & 1 \\
TP53 & $3^{*}$ & 0 \\
ATM & 1 & 0 \\
MDM2 & 1 & 2 \\
MDM4 & 0 & $2 \#$ \\
CDKN2A & 0 & $2 \#$ \\
CREBBP & 0 & 1 \\
\hline
\end{tabular}

* In the study group, one case harbored two mutations (ALK and TP53). \# In the control group, three cases harbored two mutations (ALK and MDM4; ALK and CDKN2A; HRAS and NF1).

\subsection{Treatment and Overall Outcome}

Eighty percent of the study group had received high-dose chemotherapy with autologous stem cell support. Infants $<6$ months at diagnosis had been excluded by protocol. Sixteen percent received antibody treatment, $10 \%{ }^{131} \mathrm{mIBG}$ therapy, and $7 \%$ percutaneous irradiation. The 10-year EFS of the study group was 47\% (95\% CI 39-54\%), and 10-year OS was $56 \%$ (95\% CI $49-63 \%)$, which was significantly better than that of the control group (10-year EFS 25\%, 95\% CI 18-31\%; 10-year OS 32\%, 95\% CI 25-39\%, both log-rank $p<0.001$ ) (Figure 2). In both groups death was caused by tumor progression in $87 \%$, while $13 \%$ of deaths were due to treatment toxicity or could not be distinguished between tumor progression and toxicity (Table 1 ).

\subsection{Impact of Clinical and Biological Characteristics on Outcome in the Study Group}

Study group patients with stage 4 disease had an inferior 10-year EFS and tended to have a lower OS in comparison to patients with stages 1-3 or 4S (log-rank $p=0.038$ and $p=0.077$, respectively; Supplementary Figure S1). No impact on EFS of the study group was observed for the characteristics age at diagnosis (independent of the age threshold 12, 18 , or 24 months, $p=0.672, p=0.058, p=0.230$, respectively), elevation of catecholamine metabolites (VMA/HVA) or ferritin (log-rank $p=0.541$ and $p=0.865$, respectively), and chromosome $1 \mathrm{p}$ status (normal vs. imbalance, $\log$-rank $p=0.635$; normal vs. deletion, $p=0.660$; imbalance vs. deletion, $p=0.659)$. By contrast, mutations of RAS or $\mathrm{p} 53$ pathway genes were strongly associated with an unfavorable outcome (10-year EFS, $19 \%$ vs. $55 \%$, 10 -year OS, $19 \%$ vs. $67 \%$, both $p<0.001$; Figure 3). Patients whose tumors harbored $A L K$ mutations had similarly poor outcome as those whose tumors harbored alterations of other RAS or p53 pathway-related genes ( $p=0.624$ for EFS and $p=0.425$ for OS). In the control group a similar, albeit less pronounced, prognostic effect of mutations in RAS-/p53 pathway-related genes was observed (10-year EFS 16\% vs. 33\%, log-rank $p=0.063 ; 10$-year OS $21 \%$ vs. $57 \%$, log-rank $p=0.008$ ).

\subsection{Therapy-Related Risk Factors}

Patients with macroscopically complete resection of the primary tumor ( $47 \%$ of patients) had both better EFS and OS than those with incomplete resection (35\%), biopsy only $(10 \%)$, or no surgical intervention ( $8 \%$; Figure 4$)$. Within the group of patients with incompletely resected primary tumors, the outcome was not different between biopsy and macroscopically incomplete resection (log-rank EFS $p=0.989, \log$-rank OS $p=0.629$ ). 
Since stage 1 corresponds to macroscopically complete resection by definition, we excluded these patients $(N=5)$. In the remaining stage-defined groups, macroscopically complete resection was associated with better outcome in stage 3 patients ( $p<0.001$ for EFS, $p<0.001$ for OS; $N=68$ ), stage 4 S patients ( $p=0.013$ for EFS, $p=0.006$ for OS; $N=26$ ), and stage 4 patients aged $<18$ months ( $p=0.056$ for EFS, $p=0.012$ for OS; $N=71$ ), while it was not prognostic in stage 2 patients ( $p=0.685$ for EFS, $p=0.553$ for OS; $N=20$; Supplementary Figure S2).

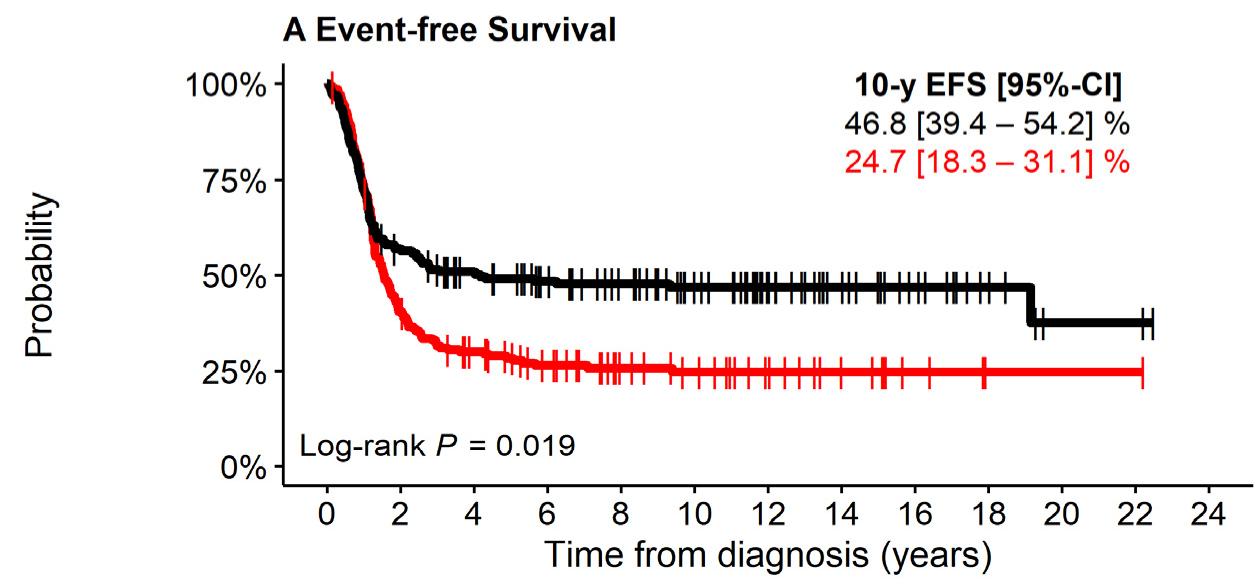

Numbers at risk

$\begin{array}{rccccccccccccc}\text { Control group } & 205 & 82 & 56 & 41 & 28 & 23 & 16 & 9 & 4 & 1 & 1 & 1 & 0 \\ \text { Study group } & 190 & 105 & 86 & 73 & 62 & 48 & 33 & 22 & 14 & 7 & 2 & 2 & 0\end{array}$

\section{B Overall Survival}

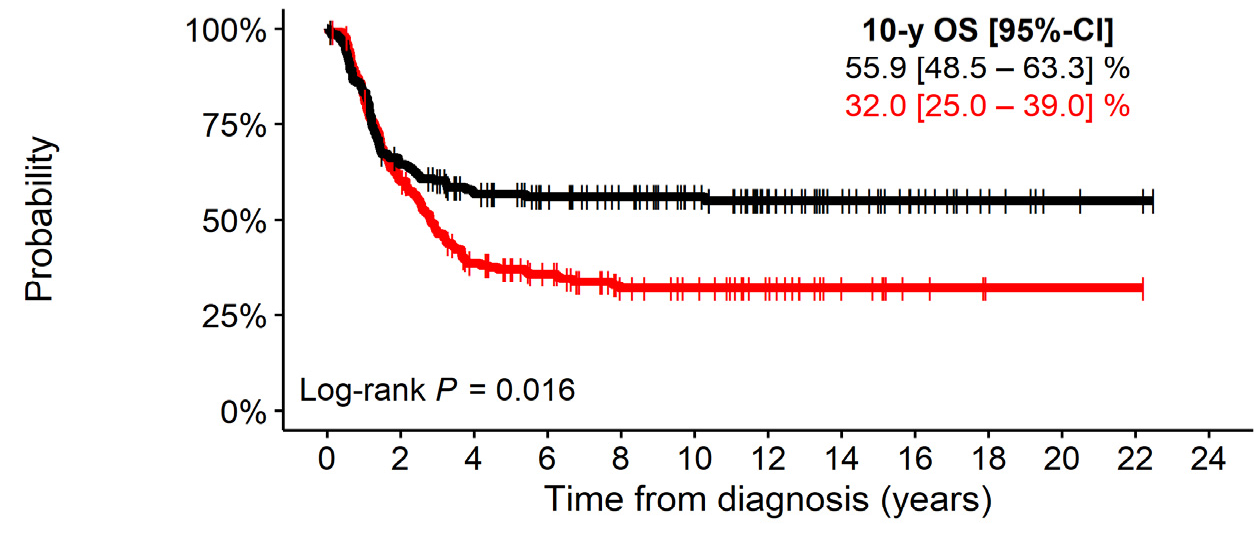

\section{Numbers at risk}

$\begin{array}{rccccccccccccc}\text { Control group } & 205 & 121 & 72 & 55 & 35 & 29 & 20 & 9 & 4 & 1 & 1 & 1 & 0 \\ \text { Study group } & 190 & 119 & 95 & 82 & 70 & 56 & 40 & 27 & 17 & 8 & 3 & 2 & 0\end{array}$

Figure 2. EFS and OS of 190 study patients attributed to high-risk solely due to MNA (black), 205 patients with stage 4 aged $>18$ months at diagnosis and MNA (control group, red). (A) Event-free Survival. (B) Overall Survival. 


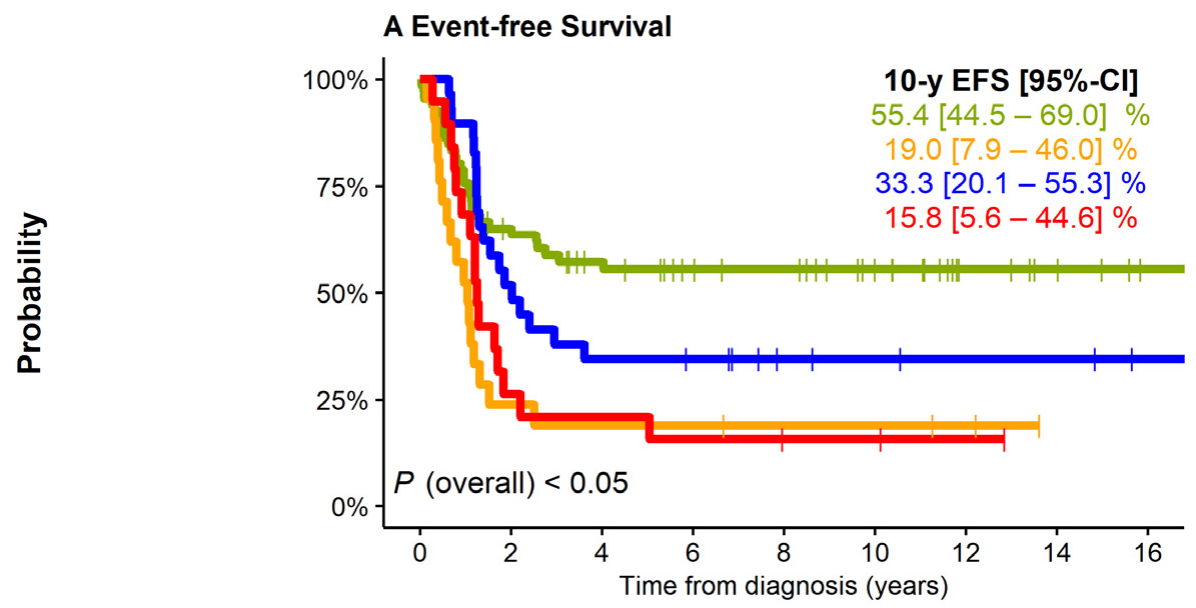

Numbers at risk

$\begin{array}{rccccccccc}\text { Study group, no mutation } & 66 & 41 & 32 & 26 & 24 & 17 & 8 & 5 & 1 \\ \text { Study group, mutation } & 21 & 5 & 4 & 4 & 3 & 3 & 2 & 0 & 0 \\ \text { Control group, no mutation } & 29 & 15 & 10 & 9 & 5 & 4 & 3 & 3 & 1 \\ \text { Control group, mutation } & 19 & 5 & 4 & 3 & 2 & 2 & 1 & 0 & 0\end{array}$

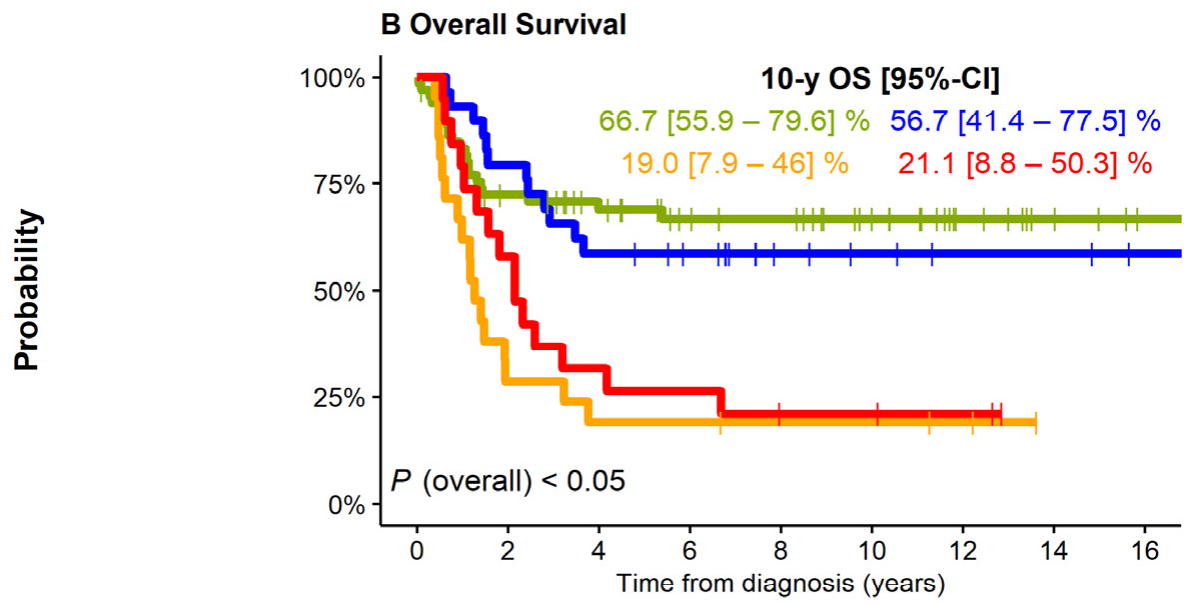

\section{Numbers at risk}

$\begin{array}{rccccccccc}\text { Study group, no mutation } & 66 & 45 & 37 & 29 & 27 & 19 & 10 & 5 & 1 \\ \text { Study group, mutation } & 21 & 6 & 4 & 4 & 3 & 3 & 2 & 0 & 0 \\ \text { Control group, no mutation } & 29 & 23 & 17 & 14 & 7 & 5 & 3 & 3 & 1 \\ \text { Control group, mutation } & 19 & 11 & 6 & 5 & 3 & 3 & 2 & 0 & 0\end{array}$

Figure 3. EFS and OS of 87 study group $(N=87)$ and control group $(N=39)$ patients by the presence of mutations in the genes of the RAS and p53 pathways (including ALK). (A): EFS, (B): OS. Pairwise comparisons (Log-rank $p$-values, Bonferroni-Holm adjusted). EFS: Study group, no mutation vs. study group, mutation: 0.003 . Study group, no mutation vs. control group, no mutation: N.A. (lines cross). Study group, no mutation vs. control group, mutation: 0.012 . Study group, mutation vs. control group, no mutation: 0.028 . Study group, mutation vs. control group, mutation: 0.510 . Control group, no mutation vs. control group, mutation: 0.094. OS: Study group, no mutation vs. study group, mutation: $<0.001$. Study group, no mutation vs. control group, no mutation: N.A. (lines cross). Study group, no mutation vs. control group, mutation: 0.003 . Study group, mutation vs. control group, no mutation: 0.001 . Study group, mutation vs. control group, mutation: 0.393 . Control group, no mutation vs. control group, mutation: 0.013 . 


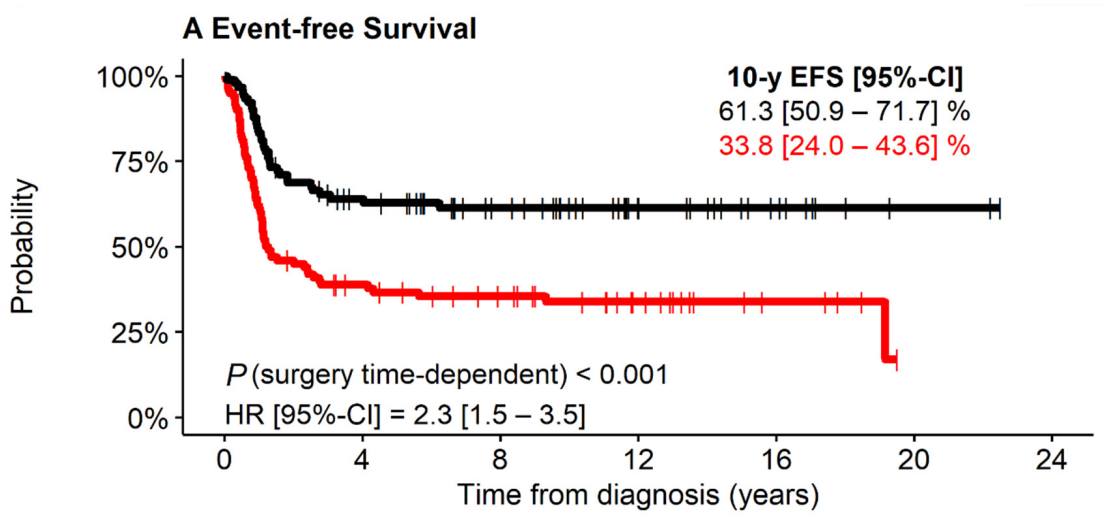

Numbers at risk (study group)

$\begin{array}{rccccccc}\text { Incomplete/ } & 100 & 35 & 26 & 15 & 5 & 0 & 0 \\ \text { biopsy/none } & 100 & 51 & 36 & 18 & 9 & 2 & 0 \\ \text { Complete } & 90 & 51 & \end{array}$

B Overall Survival

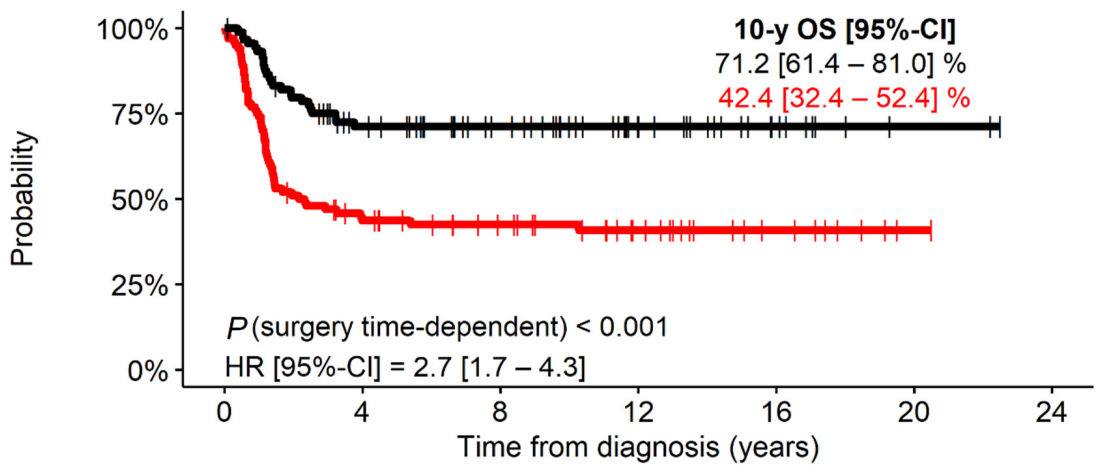

Numbers at risk (study group)

$\begin{array}{rrrrrrrr}\text { Incomplete/ } & & & & & 1 & 0 \\ \text { biopsy/none } & 100 & 40 & 30 & 19 & 8 & 1 & 0 \\ \text { Complete } & 90 & 55 & 40 & 21 & 9 & 2 & 0\end{array}$

Figure 4. EFS and OS of 190 study group patients with MYCN amplification and stages 1, 2, 3, 4S or stage 4 aged $<18$ months by completeness of surgical resection *. * If more than one surgical intervention, the best result was counted. (A) Event-free Survival. (B) Overall survival.

High-dose chemotherapy was associated with both better EFS and OS (likelihood ratios $p<0.001$ ), while antibody therapy was not (likelihood ratio EFS $p=0.133$; likelihood ratio OS $p=0.083$ ). Intravenous systemic ${ }^{131} \mathrm{mIBG}$ radiotherapy and percutaneous irradiation were given only in the case of active residual tumor following induction chemotherapy, and they were associated with similar (likelihood ratio $p=0.459$ ) and worse outcome (likelihood ratio $p=0.026$ ), respectively, compared to non-irradiated patients.

\subsection{Definition of Risk Groups}

To define risk groups within the study group, we performed multivariable analysis based on EFS and OS. The multivariable model based on EFS revealed that 'mutation in RAS-/p53 pathway genes' was the only independent prognostic marker for poor outcome, whereas both 'mutation in RAS-/p53 pathway genes' and 'less than complete resection of the primary tumor' were independent prognostic markers for poor OS (Table 3; Supplementary Figure S3). Notably, OS of patients with complete resection of the primary tumor and no mutation, who comprised more than one-third of the cohort, was $>80 \%$. When the mutation status was not available, the variables 'stage' and 'best surgery' were independent prognostic markers for EFS as well as OS (Table 3). 
Table 3. Multivariable analysis of time-independent and time-dependent risk factors of the study group patients.

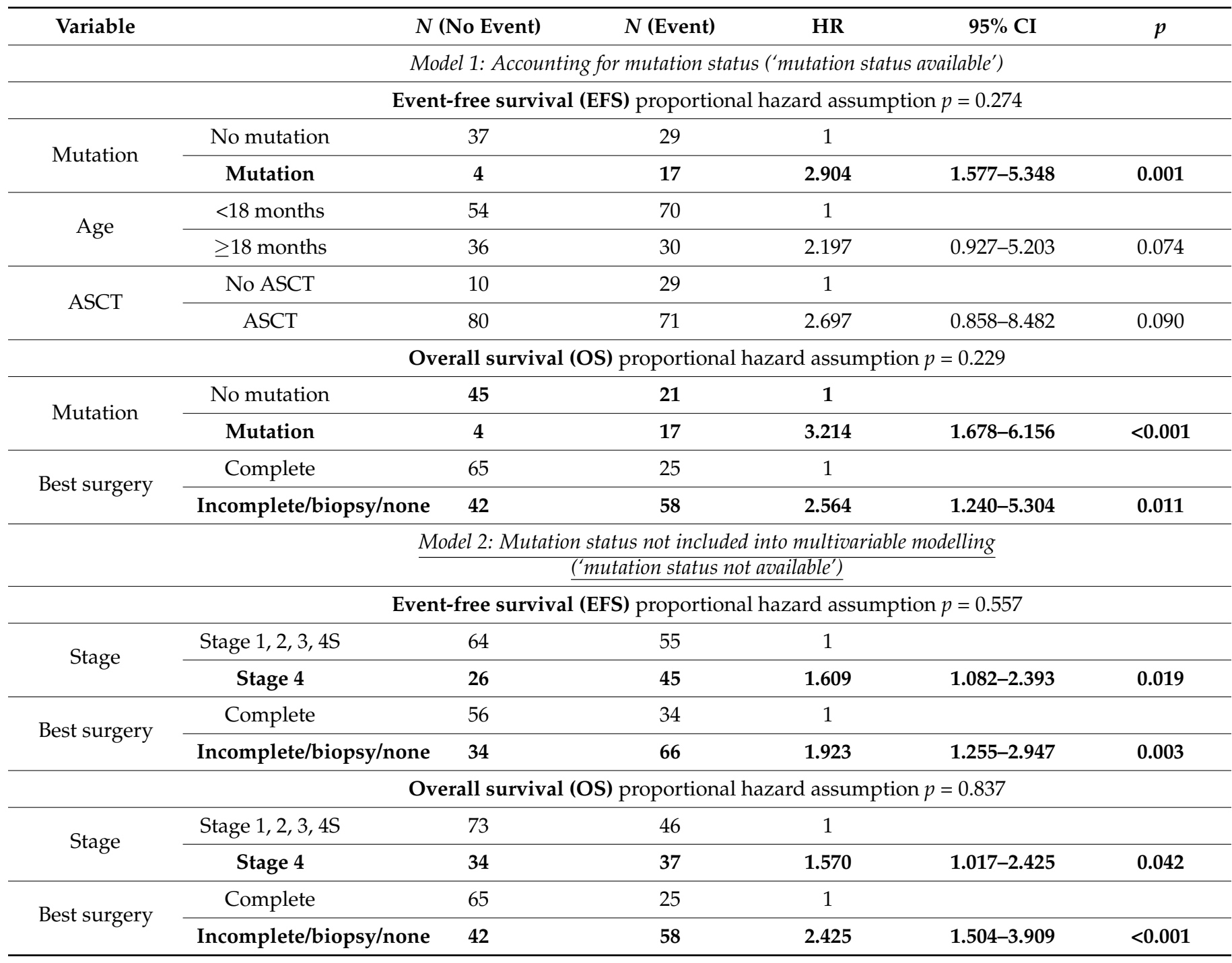

\subsection{Tumor Recurrences}

Tumor recurrences were observed in 88 patients after a median time of 12 months (Table 4$)$, which was shorter than in the control group (15 months, $p=0.003)$. The main recurrence sites were the primary site $(66 \%)$, osteomedullary $(35 \%)$, central nervous system $(20 \%)$, liver $(20 \%)$, and lymph nodes $(15 \%)$. Forty-five percent of the relapsed patients had recurrences in more than one site. Patients in the control group more frequently had osteomedullary recurrences $(58 \%, p=0.001)$ and at the primary site $(41 \%, p=0.036)$.

Eleven of the ninety-three patients with localized neuroblastoma and 11/26 stage $4 S$ patients progressed to stage $4(12 \%$ and $42 \%$, respectively), mostly representing a spread to multiple organs (19/22 cases). Patients with localized progression had a better secondary EFS ( $\log$-rank $p=0.013)$ and OS (log-rank $p=0.010)$ compared to those with metastatic progression. The median times from the first to next recurrence or death were short (interval first to second recurrence, 2.2 months, $95 \%$ CI, 1.8-2.5; interval first recurrence to death, 4.5 months, 95\% CI, 3.6-5.4). 
Table 4. Recurrence patterns of study and control group patients.

\begin{tabular}{|c|c|c|c|}
\hline Parameter & $\begin{array}{c}\text { Study Group } \\
\text { Stages } 1,2,3, \\
4 \mathrm{~S}, 4<18 \mathrm{~m} \\
N(\%)\end{array}$ & $\begin{array}{c}\text { Control Group } \\
\text { Stage } 4 \geq 18 \mathrm{~m} \text { and } \\
\mathrm{MNA} \\
N(\%)\end{array}$ & $p$ \\
\hline Recurrences & $88(100)$ & $139(100)$ & \\
\hline Primary site & $58(66)$ & $84(60)$ & 0.036 \\
\hline Osteomedullary * & $31(35)$ & $80(58)$ & 0.001 \\
\hline Bone marrow & $20(23)$ & $62(45)$ & 0.001 \\
\hline Lymph nodes & $13(15)$ & $11(8)$ & 0.124 \\
\hline Liver & $18(20)$ & $19(14)$ & 0.202 \\
\hline Brain/spinal cord & $18(20)$ & $21(15)$ & 0.368 \\
\hline Lung/pleura & $6(7)$ & $8(6)$ & 0.783 \\
\hline Skin & $0(0)$ & $0(0)$ & N.A. \\
\hline Soft tissue & $0(0)$ & $2(1)$ & N.A. \\
\hline Other & $4(5)$ & $4(3)$ & 0.714 \\
\hline Osteomedullary only & $6(7)$ & $48(35)$ & $<0.001$ \\
\hline Primary site only & $32(36)$ & $29(21)$ & 0.014 \\
\hline \multicolumn{4}{|c|}{ Number of recurrence sites } \\
\hline 1 & $49(55)$ & $59(42)$ & \multirow{2}{*}{0.077} \\
\hline$>1$ & $40(45)$ & $80(58)$ & \\
\hline Median time ${ }^{* *}(\mathrm{~d})$ & 382 & 455 & \multirow{2}{*}{0.003} \\
\hline $\min -\max$ & $28-3407$ & $60-3427$ & \\
\hline \multicolumn{4}{|l|}{ EFS and OS } \\
\hline $5 y-\operatorname{secEFS}{ }^{* * *}(\%)$ & $13.0(5.6-20.4)$ & $10.2(5.0-15.4)$ & $0.005^{\dagger}$ \\
\hline $5 y-\sec O S(\%)$ & $14.4(6.6-22.2)$ & $9.8(4.6-15.0)$ & $0.124^{\dagger}$ \\
\hline $10 y-\operatorname{secEFS}(\%)$ & $13.0(5.6-20.4)$ & $10.2(5.0-15.4)$ & $0.005^{+}$ \\
\hline $10 \mathrm{y}-\sec \mathrm{OS}(\%)$ & $14.4(6.6-22.2)$ & $9.8(4.6-15.0)$ & $0.124^{\dagger}$ \\
\hline
\end{tabular}

${ }^{\dagger}$ Generalized Wilcoxon test; * by mIBG scintigraphy; ${ }^{* *}$ time from first diagnosis to first recurrence (days); *** secondary EFS; Secondary malignancy: 0 (exclusion criterium); Ganglioneuroma: 0.

\section{Discussion}

We here demonstrate that the outcome of neuroblastoma patients who are considered high-risk only due to MNA is substantially better than that of other high-risk patients. We also found that alterations of genes of the RAS and the p53 pathways were strong prognostic markers in this patient cohort: If such mutations were present in the tumor, the outcome of patients was very poor, whereas the majority of patients survived if such mutations were absent. Since several of the detected alterations represent actionable targets, particularly mutated $A L K[29,30]$, we suggest that integration of targeted therapies into frontline treatment should be considered in this patient subgroup in the future. In addition, complete resection of the primary tumor was an independent prognostic marker for the entire study cohort and, most importantly, also within subgroups defined by the stages $3,4 \mathrm{~S}$, and 4 . While it remains speculative whether this prognostic effect is due to surgery itself, response to chemotherapy, and/or differences in the biology of completely and incompletely resected tumors, it is a clinically relevant finding that may guide treatment decisions in these patients in future clinical trials. Nonetheless, the data indicate that complete resection of the primary tumor is likely to improve outcome in this specific cohort of patients and surgeons encouraged accordingly (without increasing the risk for life and organs). If information on genetic alterations was not available, stage was an independent prognostic marker, in addition to complete resection. Together, our data suggest that alterations of a defined set of RAS and p53 pathway-related genes should be determined at the time of diagnosis in these patients to assess their individual risk, and that complete resection should be aimed for in the treatment concept.

The 10-year EFS and OS of $47 \%$ and $56 \%$, respectively, in the study group is well in line with other reports on localized neuroblastoma with $M Y C N$ amplification. Bagatell et al. reported a 5-year EFS and OS of $53 \pm 8 \%$ and $72 \pm 7 \%$, respectively, for stage 1 and 2 patients 
with MNA tumors, compared to $90 \pm 1 \%$ and $98 \pm 1 \%$, respectively, in patients with non-amplified tumors ( $n=8800$ patients, collected in the international INRG database) [4]. MYCN amplification was also predictive for a poorer outcome in stage 3 patients of the same cohort (5-year EFS and OS with MYCN amplification $45 \pm 4 \%$ and $48 \pm 4 \%$, respectively, vs. $81 \pm 1 \%$ and $89 \pm 2 \%$ without $M Y C N$ amplification, respectively) [5]. Since Germany contributed to the international cohort collected in the INRG database, a certain overlap between the reported groups should be considered. In line with these figures, the SIOPEN group reported 71\% 5-year EFS for stage 2 and 3 MNA neuroblastoma [31]. Similar to these observations, two additional studies reported a poorer outcome in small cohorts of stage 3 patients when MYCN amplification was present in the tumors [6,7]. EFS and OS at 5 years was also lower in 6 infants with localized MNA neuroblastoma (50\% and $67 \%$, respectively) in comparison to 340 children without MNA ( $95 \%$ and $98 \%$, respectively) in a Japanese study [8].

The strengths of this study are (i) the fact that $99 \%$ of patients diagnosed during the study periods were covered [13], (ii) the availability of corresponding clinical and molecular characteristics, and (iii) a largely uniform and modern treatment schedule. It has to be noted, however, that the treatment regimens applied to patients were not completely identical, although these differences had no impact on patient outcome in the respective trials $[24,25]$. Another potential limitation of the study is the fact that the results have been obtained retrospectively and should thus be considered as descriptive (although data had been collected prospectively). We therefore suggest to validate our findings in a prospective study. Finally, the Cox model estimates may be unstable due to the low number in some groups

\section{Conclusions}

Our study demonstrates that RAS and p53 pathway alterations have a strong impact on outcome of neuroblastoma patients assigned to high-risk solely by the presence of MNA. We therefore suggest to complement MYCN diagnostics by investigating genetic alterations of a predefined set of genes related to the RAS and p53 pathways. For routine clinical care, stage and resectability of the primary tumor are the important risk factors, and information on these is always available.

Supplementary Materials: The following are available online at https://www.mdpi.com/article/ 10.3390/cancers13174360/s1, Figure S1: EFS and OS of 190 study group patients with MYCN amplification by stage (1, 2, 3, $4 \mathrm{~S}$ vs. stage 4 aged $<18$ months), Figure S2: EFS and OS of 185 study group patients by stage and best result of surgical resection, Figure S3: EFS and OS of 87 study group patients by independent risk factors 'presence of mutation' and 'best result of surgical resection' *.

Author Contributions: The study concept, the data acquisition, and interpretation were elaborated by all authors (F.B., A.E., S.A., C.B., H.C., B.H., C.R., D.v.S., T.K., I.S., T.S. and M.F.) and resulted from being an active member of the trial committee and from treatment experiences obtained in a major institution. C.R., S.A., C.B. and M.F. performed molecular analyses. B.H. and T.S. were trial coordinators, A.E., C.B. and F.B. did statistical analyses. Manuscript preparation was done by F.B. and M.F. All authors (F.B., A.E., S.A., C.B., H.C., B.H., C.R., D.v.S., T.K., I.S., T.S. and M.F.) reviewed and approved the final version. F.B. was the principal investigator of the trials, had access to all data and the final responsibility for the decision to submit for publication. All authors have read and agreed to the published version of the manuscript.

Funding: This research received external funding. The work of CR was supported by the Else Kröner-Fresenius Foundation (2016-Kolleg-19). The Neuroblastoma trial NB97 was supported by the German Cancer Aid (Grant 70-2290-Be) and by the German Children's Cancer Aid (Grants 96.06 and 99.03). Neuroblastoma trial NB2004 was supported by the German Cancer Aid (Grant (70107712) to FB.

Institutional Review Board Statement: Both the NB97 and 2004-HR trials were conducted according to the guidelines for Good Clinical Practice (ICH-GCP), the applicable national legislations, and the Declaration of Helsinki (version 2002, Washington). They were approved by the national regulatory 
authorities and by the ethical committee of the University of Cologne (9764 for NB97 and 04049 for NB2004-HR). The trials are registered at Clinical Trials.gov (Identifier NCT00526318 NB97, NCT03042429 NB2004-HR).

Informed Consent Statement: Informed consent was obtained from all patients or their guardians for participation in the study design, data collection and treatment.

Data Availability Statement: All clinical data are contained within the article or the supplementary material. Molecular data are available from the authors upon reasonable request.

Acknowledgments: The authors thank very much Kathy Taylor for English editing.

Conflicts of Interest: The authors declare no conflict of interest. They have no known competing financial interests or personal relationships that could have appeared to influence the work reported in this paper. The funders of the study had no role in the study design, data collection, data analysis, data interpretation, or writing of the report. The corresponding author had full access to all the data in the study and had the final responsibility for the decision to submit for publication.

\section{References}

1. Park, J.R.; Bagatell, R.; Cohn, S.L.; Pearson, A.D.; Villablanca, J.G.; Berthold, F.; Burchill, S.; Boubaker, A.; McHugh, K.; Nuchtern, J.G.; et al. Revisions to the International Neuroblastoma Response Criteria: A Consensus Statement From the National Cancer Institute Clinical Trials Planning Meeting. J. Clin. Oncol. 2017, 35, 2580-2587. [CrossRef]

2. Cohn, S.L.; Pearson, A.D.; London, W.B.; Monclair, T.; Ambros, P.F.; Brodeur, G.M.; Faldum, A.; Hero, B.; Iehara, T.; Machin, D.; et al. The International Neuroblastoma Risk Group (INRG) classification system: An INRG Task Force report. J. Clin. Oncol. 2009, 27, 289-297. [CrossRef]

3. Maris, J.M. Recent advances in neuroblastoma. N. Engl. J. Med. 2010, 362, 2202-2211. [CrossRef]

4. Bagatell, R.; Beck-Popovic, M.; London, W.B.; Zhang, Y.; Pearson, A.D.; Matthay, K.K.; Monclair, T.; Ambros, P.F.; Cohn, S.L. Significance of MYCN amplification in international neuroblastoma staging system stage 1 and 2 neuroblastoma: A report from the International Neuroblastoma Risk Group database. J. Clin. Oncol. 2009, 27, 365-370. [CrossRef]

5. Meany, H.J.; London, W.B.; Ambros, P.F.; Matthay, K.K.; Monclair, T.; Simon, T.; Garaventa, A.; Berthold, F.; Nakagawara, A.; Cohn, S.L.; et al. Significance of clinical and biologic features in Stage 3 neuroblastoma: A report from the International Neuroblastoma Risk Group project. Pediatr. Blood Cancer 2014, 61, 1932-1939. [CrossRef]

6. Modak, S.; Kushner, B.H.; LaQuaglia, M.P.; Kramer, K.; Cheung, N.K. Management and outcome of stage 3 neuroblastoma. Eur. J. Cancer 2009, 45, 90-98. [CrossRef]

7. Park, J.R.; Villablanca, J.G.; London, W.B.; Gerbing, R.B.; Haas-Kogan, D.; Adkins, E.S.; Attiyeh, E.F.; Maris, J.M.; Seeger, R.C.; Reynolds, C.P.; et al. Outcome of high-risk stage 3 neuroblastoma with myeloablative therapy and 13-cis-retinoic acid: A report from the Children's Oncology Group. Pediatr. Blood Cancer 2009, 52, 44-50. [CrossRef] [PubMed]

8. Iehara, T.; Hamazaki, M.; Tajiri, T.; Kawano, Y.; Kaneko, M.; Ikeda, H.; Hosoi, H.; Sugimoto, T.; Sawada, T.; Japanese Infantile Neuroblastoma Cooperative Study Group. Successful treatment of infants with localized neuroblastoma based on their MYCN status. Int. J. Clin. Oncol. 2013, 18, 389-395. [CrossRef] [PubMed]

9. De Bernardi, B.; Di Cataldo, A.; Garaventa, A.; Massirio, P.; Viscardi, E.; Podda, M.G.; Castellano, A.; D’Angelo, P.; Tirtei, E.; Melchionda, F.; et al. Stage 4 s neuroblastoma: Features, management and outcome of 268 cases from the Italian Neuroblastoma Registry. Ital. J. Pediatr. 2019, 45, 8. [CrossRef] [PubMed]

10. Schleiermacher, G.; Rubie, H.; Hartmann, O.; Bergeron, C.; Chastagner, P.; Mechinaud, F.; Michon, J.; Neuroblastoma Study Group of the French Society of Paediatric Oncology. Treatment of stage 4s neuroblastoma-Report of 10 years' experience of the French Society of Paediatric Oncology (SFOP). Br. J. Cancer 2003, 89, 470-476. [CrossRef]

11. Bagatell, R.; Rumcheva, P.; London, W.B.; Cohn, S.L.; Look, A.T.; Brodeur, G.M.; Frantz, C.; Joshi, V.; Thorner, P.; Rao, P.V.; et al. Outcomes of children with intermediate-risk neuroblastoma after treatment stratified by MYCN status and tumor cell ploidy. $J$. Clin. Oncol. 2005, 23, 8819-8827. [CrossRef]

12. Schmidt, M.L.; Lukens, J.N.; Seeger, R.C.; Brodeur, G.M.; Shimada, H.; Gerbing, R.B.; Stram, D.O.; Perez, C.; Haase, G.M.; Matthay, K.K. Biologic factors determine prognosis in infants with stage IV neuroblastoma: A prospective Children's Cancer Group study. J. Clin. Oncol. 2000, 18, 1260-1268. [CrossRef]

13. Berthold, F.; Spix, C.; Kaatsch, P.; Lampert, F. Incidence, Survival, and Treatment of Localized and Metastatic Neuroblastoma in Germany 1979-2015. Paediatr. Drugs 2017, 19, 577-593. [CrossRef] [PubMed]

14. Holmes, K.; Potschger, U.; Pearson, A.D.J.; Sarnacki, S.; Cecchetto, G.; Gomez-Chacon, J.; Squire, R.; Freud, E.; Bysiek, A.; Matthyssens, L.E.; et al. Influence of Surgical Excision on the Survival of Patients with Stage 4 High-Risk Neuroblastoma: A Report From the HR-NBL1/SIOPEN Study. J. Clin. Oncol. 2020, 38, 2902-2915. [CrossRef]

15. Du, L.; Liu, L.; Zhang, C.; Cai, W.; Wu, Y.; Wang, J.; Lv, F. Role of surgery in the treatment of patients with high-risk neuroblastoma who have a poor response to induction chemotherapy. J. Pediatr. Surg. 2014, 49, 528-533. [CrossRef]

16. Simon, T.; Haberle, B.; Hero, B.; von Schweinitz, D.; Berthold, F. Role of surgery in the treatment of patients with stage 4 neuroblastoma age 18 months or older at diagnosis. J. Clin. Oncol. 2013, 31, 752-758. [CrossRef] [PubMed] 
17. Mullassery, D.; Farrelly, P.; Losty, P.D. Does aggressive surgical resection improve survival in advanced stage 3 and 4 neuroblastoma? A systematic review and meta-analysis. Pediatr. Hematol. Oncol. 2014, 31, 703-716. [CrossRef]

18. McGregor, L.M.; Rao, B.N.; Davidoff, A.M.; Billups, C.A.; Hongeng, S.; Santana, V.M.; Hill, D.A.; Fuller, C.; Furman, W.L. The impact of early resection of primary neuroblastoma on the survival of children older than 1 year of age with stage 4 disease: The St. Jude Children's Research Hospital Experience. Cancer 2005, 104, 2837-2846. [CrossRef] [PubMed]

19. Ackermann, S.; Cartolano, M.; Hero, B.; Welte, A.; Kahlert, Y.; Roderwieser, A.; Bartenhagen, C.; Walter, E.; Gecht, J.; Kerschke, L.; et al. A mechanistic classification of clinical phenotypes in neuroblastoma. Science 2018, 362, 1165-1170. [CrossRef]

20. Ney, G.M.; McKay, L.; Koschmann, C.; Mody, R.; Li, Q. The Emerging Role of Ras Pathway Signaling in Pediatric Cancer. Cancer Res. 2020, 80, 5155-5163. [CrossRef]

21. Peifer, M.; Hertwig, F.; Roels, F.; Dreidax, D.; Gartlgruber, M.; Menon, R.; Kramer, A.; Roncaioli, J.L.; Sand, F.; Heuckmann, J.M.; et al. Telomerase activation by genomic rearrangements in high-risk neuroblastoma. Nature 2015, 526, 700-704. [CrossRef] [PubMed]

22. Brodeur, G.M.; Pritchard, J.; Berthold, F.; Carlsen, N.L.; Castel, V.; Castelberry, R.P.; De Bernardi, B.; Evans, A.E.; Favrot, M.; Hedborg, F.; et al. Revisions of the international criteria for neuroblastoma diagnosis, staging, and response to treatment. J. Clin. Oncol. 1993, 11, 1466-1477. [CrossRef] [PubMed]

23. Ambros, P.F.; Ambros, I.M.; SIOP Europe Neuroblastoma Pathology, Biology, and Bone Marrow Group. Pathology and biology guidelines for resectable and unresectable neuroblastic tumors and bone marrow examination guidelines. Med. Pediatr. Oncol. 2001, 37, 492-504. [CrossRef] [PubMed]

24. Berthold, F.; Faldum, A.; Ernst, A.; Boos, J.; Dilloo, D.; Eggert, A.; Fischer, M.; Fruhwald, M.; Henze, G.; Klingebiel, T.; et al. Extended induction chemotherapy does not improve the outcome for high-risk neuroblastoma patients: Results of the randomized open-label GPOH trial NB2004-HR. Ann. Oncol. 2020, 31, 422-429. [CrossRef]

25. Berthold, F.; Ernst, A.; Hero, B.; Klingebiel, T.; Kremens, B.; Schilling, F.H.; Simon, T. Long-term outcomes of the GPOH NB97 trial for children with high-risk neuroblastoma comparing high-dose chemotherapy with autologous stem cell transplantation and oral chemotherapy as consolidation. Br. J. Cancer 2018, 119, 282-290. [CrossRef] [PubMed]

26. Ambros, P.F.; Ambros, I.M.; Brodeur, G.M.; Haber, M.; Khan, J.; Nakagawara, A.; Schleiermacher, G.; Speleman, F.; Spitz, R.; London, W.B.; et al. International consensus for neuroblastoma molecular diagnostics: Report from the International Neuroblastoma Risk Group (INRG) Biology Committee. Br. J. Cancer 2009, 100, 1471-1482. [CrossRef]

27. Mac, S.M.; D'Cunha, C.A.; Farnham, P.J. Direct recruitment of N-myc to target gene promoters. Mol. Carcinog. 2000, 29, 76-86. [CrossRef]

28. Shimada, H.; Ambros, I.M.; Dehner, L.P.; Hata, J.; Joshi, V.V.; Roald, B. Terminology and morphologic criteria of neuroblastic tumors: Recommendations by the International Neuroblastoma Pathology Committee. Cancer 1999, 86, 349-363. [CrossRef]

29. Mosse, Y.P.; Lim, M.S.; Voss, S.D.; Wilner, K.; Ruffner, K.; Laliberte, J.; Rolland, D.; Balis, F.M.; Maris, J.M.; Weigel, B.J.; et al. Safety and activity of crizotinib for paediatric patients with refractory solid tumours or anaplastic large-cell lymphoma: A Children's Oncology Group phase 1 consortium study. Lancet Oncol. 2013, 14, 472-480. [CrossRef]

30. Schulte, J.H.; Schulte, S.; Heukamp, L.C.; Astrahantseff, K.; Stephan, H.; Fischer, M.; Schramm, A.; Eggert, A. Targeted Therapy for Neuroblastoma: ALK Inhibitors. Klin. Padiatr. 2013, 225, 303-308. [CrossRef]

31. Ladenstein, R.; Potschger, U.; Pearson, A.D.J.; Brock, P.; Luksch, R.; Castel, V.; Yaniv, I.; Papadakis, V.; Laureys, G.; Malis, J.; et al. Busulfan and melphalan versus carboplatin, etoposide, and melphalan as high-dose chemotherapy for high-risk neuroblastoma (HR-NBL1/SIOPEN): An international, randomised, multi-arm, open-label, phase 3 trial. Lancet Oncol. 2017, 18, 500-514. [CrossRef] 